\title{
Chloro-karboniel vastetoestand-wanordebepaling in Vaska tipe komplekse
}

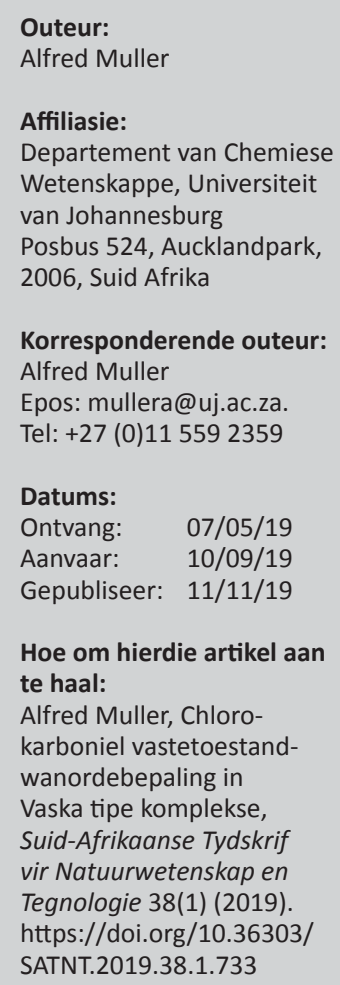

Korresponderende outeur: Alfred Muller Epos: mullera@uj.ac.za. Tel: +27 (0)11 5592359

\section{Datums:}

Ontvang: $\quad$ 07/05/19

Aanvaar: $\quad 10 / 09 / 19$

Gepubliseer: 11/11/19

Hoe om hierdie artikel aan te haal:

Alfred Muller, Chlorokarboniel vastetoestandwanordebepaling in Vaska tipe komplekse, Suid-Afrikaanse Tydskrif vir Natuurwetenskap en Tegnologie 38(1) (2019). https://doi.org/10.36303/ SATNT.2019.38.1.733

An English copy of this paper is available online at http://www.satnt.ac.za/ index.php/satnt/article/ view/733

\section{Kopiereg:}

(C) 2019. Authors.

Licensee: Die SuidAfrikaanse Akademie vir Wetenskap en Kuns. Hierdie werk is onder die Creative Commons Attribution License gelisensieer. 'n Ondersoek na die effek van gemengde feniel-sikloheksiel gesubstitueerde ariel tersiêre fosfiene op die vastetoestandwanorde van die $\mathrm{Cl}-\mathrm{Rh}-\mathrm{CO}$-groep in Vaska-tipe komplekse trans- $\left[\mathrm{M}(\mathrm{CO}) \mathrm{Cl}\left(\mathrm{PPh}_{\mathrm{n}} \mathrm{Cy}_{3-\mathrm{n}}\right)_{2}\right]$, waar $\mathrm{M}=\mathrm{Rh}(\mathrm{I})$ of $\mathrm{Ir}(\mathrm{I}), \mathrm{Ph}=\mathrm{C}_{6} \mathrm{H}_{5}, \mathrm{Cy}=\mathrm{C}_{6} \mathrm{H}_{11}$ en $\mathrm{n}=1$ of 2, word aangebied. Enkelkristal X-straalstrukture van 4 voorbeelde van die reeks word geraporteer en vergelyk met verwante strukture wat dikwels die wanorde van die $\mathrm{Cl}-\mathrm{Rh}-\mathrm{CO}$-groep, wat deur kristallografiese simmetrie beheer word, openbaar. Digtheids funksionele teorie (DFT) geometrie-optimalisering en energieberekenings op konformere van hierdie komplekse dui aan dat die wanorde waarskynlik is. 'n Onverwagte vastetoestandwanorde tussen feniel- en sikloheksielsubstituente van die fosfiene word ook bespreek.

Sleutelwoorde: Vaska; wanorde, X-straalstruktuur; DFT berekening

Chloro-carbonyl disorder determination in Vaska-type complexes: An investigation into the effect of mixed phenyl-cyclohexyl substituted aryl tertiary phosphines on the disorder of the Cl-Rh-CO moiety in Vaska-type complexes trans-[M(CO) $\left.\mathrm{Cl}\left(\mathrm{PPh}_{\mathrm{n}} \mathrm{Cy}_{3-\mathrm{n}}\right)_{2}\right]$, where $\mathrm{M}=$ $\mathrm{Rh}(\mathrm{I})$ or $\operatorname{Ir}(\mathrm{I}), \mathrm{Ph}=\mathrm{C}_{6} \mathrm{H}_{5}, \mathrm{Cy}=\mathrm{C}_{6} \mathrm{H}_{11}$ and $\mathrm{n}=1$ or 2 , is presented. Single crystal X-ray analysis of four examples of the series is reported and compared with related structures which often reveal disorder of the $\mathrm{Cl}-\mathrm{Rh}-\mathrm{CO}$ moiety, governed by crystallographic symmetry. DFT geometry optimisations and energy calculations on conformers of these complexes are within reasonable agreement that the disorder is likely. An unexpected disorder between phenyl and cyclohexyl substituents of the phosphines is also discussed.

Keywords: Vaska, disorder, X-ray structure, DFT calculation

\section{Inleiding}

Komplekse met die algemene formule trans- $\left[\mathrm{Rh}(\mathrm{CO}) \mathrm{X}(\mathrm{L})_{2}\right](\mathrm{X}=$ halied of pseudo-halied; $\mathrm{L}=$ ariel of alkiel gesubstitueerde tersiêre fosforligand) word in baie gevalle verwys na as Vaskatipe komplekse (Ohgomori \& Watanabe, 1990, Galding et al., 2016, Smoleński et al., 2011, Roodt et al., 2003), 'n naam wat verband hou met die werk van Vaska \& DiLuzio, 1961 op die oorspronklike trans-[ $\left.\operatorname{Ir}(\mathrm{CO}) \mathrm{Cl}\left(\mathrm{PPh}_{3}\right)_{2}\right]$ kompleks. Die geskiedenis agter die benaming is ietwat omstrede, aangesien Angoletta, 1959 alreeds die kompleks twee jaar voor die werk van Vaska en DiLuzio berei het, en selfs die rhodium-analoog was alreeds gerapporteer (Vallarino, 1957) en is in ' $n$ mate deur Chatt en mede-werkers ondersoek (Winterton \& Leigh, 2002). Die volgorde van gebeure wat tot die vaspen van die naam gelei het, word uiteengesit in ' $n 50^{\text {ste }}$ herdenkingsartikel van die kompleks (Kirss, 2013); die redes word hoofsaaklik toegeskryf aan vroeëre, verkeerde identifisering van die verbinding asook die wyer impak van die tydskrif wat Vaska gebruik het. Nietemin het die Vaska-tipe komplekse wat deur Chatt bestudeer is, aansienlike bydraes gelewer tot die toepassing van teorieë wat in vandag se handboeke verskyn.

Die rhodium Vaska-tipe kompleks, trans- $\left[\mathrm{RhCl}(\mathrm{CO})\left(\mathrm{PPh}_{3}\right)_{2}\right]$, is bewys as 'n effektiewe homogene katalisator vir die hidrogenering van olefiene en asetilene in organiese oplosmiddels (Osborn et al., 1966). Die iridium Vaska-komplekse is egter selfs meer reaktief en vorm maklik addukte met talle molekule soos $\mathrm{H}_{2}, \mathrm{O}_{2}, \mathrm{SO}_{2}, \mathrm{CO}, \mathrm{HCl}$ en $\mathrm{RX}(\mathrm{R}=$ organiese fragment, $\mathrm{X}=$ halogeen) (Collman \& Hegedus, 1980). Aangesien hierdie komplekse kan deelneem aan 'n reeks elementêre reaksies, wat sleutelstappe vorm in die katalitiese sintese van organiese produkte (Pignolet, 1983), is dit dus belangrik om die eienskappe van hierdie komplekse te verstaan ten einde kinetiese beheer oor die siklus te hê. Dit is hier waar die tersiêre fosfiene 'n belangrike rol speel as gevolg van hul pasmaakvermoë, hetsy elektronies of steries, en het hul belang in die rol van katalise bewys (van Leeuwen, 2004). Alhoewel daar heelwat 
vordering gemaak is (Roodt et al., 2003, Muller et al., 2008) om die pasmaak te verstaan, bly die steriese en elektroniese eienskappe van fosfiene ' $n$ uitdaging om te identifiseer en te skei. Een van die pogings om ligandeffekte te interpreteer, is die QALE (Quantiantive Analysis of Ligand Effects) model (Fernandez et al., 2003). Hierdie benadering maak gebruik van die klassieke model van fosfor $\sigma$-skenking aan die metaalkern en $\pi$-terugdonasie van die metaalkern soos ontwikkel deur Dewar, 1951 en Chatt \& Duncanson, 1953. Dit neem ook die grootte van die ligand in ag en bevat ' $n$ steriese skakelparameter wanneer steriese effekte betekenisvol word.

Die Vaska-komplekse en hul analoë leen hulself ook tot belangrike kandidate vir die evaluering van hierdie fosfienligande, aangesien dit verskeie gerieflike peilers bevat: a) In die geval van Rh Vaska-tipe komplekse is dit die ${ }^{1} J_{\text {Rh-P }}$ koppelingswaardes in ${ }^{31} \mathrm{P}-\mathrm{KMR}$, b) by IR die $v(\mathrm{CO})$ strekkingfrekwensies wat indirek beïnvloed word deur die $\sigma$-skenkende en $\pi$-terugdonasievermoë van die fosfien en c) die maklik kristaliserende aard van Vaska-komplekse wat toegang verleen tot enkelkristal X-straalkristallografie geometriese data van beide $\mathrm{M}-\mathrm{P}$ en M-CO afstande (Roodt et al., 2003). Al hierdie tegnieke is baie sensitief vir substituentveranderings op die fosforsentrum. ' $n$ Interessante kristallografiese wanorde verskynsel pla egter Vaska se komplekse, d.i. die metaal kristalliseer op ' $n$ kristallografiese inversiepunt. Hierdie kristalsimmetrie word dan ook na die molekule oorgedra, met die metaal wat ' $n$ pseudo inversiesimmetrie aanvaar, en ook die ligandpakking wat deur inversiesimmetrie beheer word. In effek impliseer dit dat die twee fosfienligande 'n perfek- gesteierde konformasie (langs die $\mathrm{P}-\mathrm{M}-\mathrm{P}$ binding) sal hê, maar meer kommerwekkend is dat die chlorido en karboniel in die Cl-M-CO-groep sal verskyn met ' $n$ pakkingswanorde waarvan die verspreiding presies 50:50 aan beide kante van die vierkantig-planêre koördinasieomgewing is (sien Figuur 1). Hierdie rigting van die $\mathrm{Cl}-\mathrm{M}-\mathrm{CO}$ wissel nie noodwendig van elke aangrensende eenheidsel nie en kan as willekeurig beskou word. In hierdie geval dra dit egter statisties by tot ' $\mathrm{n}$ gelyke verdeling van die pakkingswanorde oor alle eenheidselle. Hierdie "gelyke" verspreiding lei dikwels tot 'n waargenome hoër kristallografiese simmetrie-element in die enkelkristal- $X$ straaldata, en dit het in die literatuur ' $n$ algemene gebruik geword om na hierdie tipe $\mathrm{Cl}-\mathrm{M}-\mathrm{CO}$-pakking in Vaskatipe komplekse te verwys as 'n statistiese wanorde as gevolg van die gepaardgaande kristallografiese simmetrie.

Dit skep dikwels problematiese verfyning van enkelkristaldata, waar soms beperkings toegepas moet word, wat minder akkurate bindingsafstande/hoeke tot gevolg het, en sodoende data onbetroubaar maak vir subtiele veranderinge wat veroorsaak word deur substituente op die fosforkern. In die geval van trans-[ $\left.\operatorname{IrCl}(\mathrm{CO})\left(\mathrm{PPh}_{3}\right)_{2}\right]$ lys die
Cambridge kristallografiese databasis (Groom et al., 2016) twee wanordelike polimorfe (Churchill et al., 1988, Blake et al., 1991) en elf inskrywings vir die Rh-PPh, Vaska-tipe analoog (Del Pra et al., 1979, Ceriotti et al., 1983, Rheingold \& Gieb, 1987, Chen et al., 1991, Kemp et al., 1995, Mills et al., 2002, Chaloner et al., 1991, Dunbar \& Haefner, 1992, Sharma et al., 1988, Lorenzini, et al., 2016, Ren et al., 2017). Vir die $\mathrm{Rh}-\mathrm{PPh}_{3}$ Vaska-tipe strukture is dié in ' $\mathrm{n}$ monokliniese ruimtegroep aangegee as nie-wanordelik, maar die trikliniese en ortorombiese voorbeelde as wanordelik. In sommige van die wanordelike gevalle is die $\mathrm{Rh}-\mathrm{Cl}$ en $\mathrm{Rh}-\mathrm{C}$ bindingsafstande van nie-wanordelike inskrywings geneem om die verfyning van beperkinge te vergemaklik. 'n Verdere soektog na Vaska-tipe komplekse met die meer lywige sikloheksiel substituent op die fosforatoom, d.i. trans$\left[\mathrm{MCl}(\mathrm{CO})\left(\mathrm{PCy}_{3}\right)_{2}\right](\mathrm{M}=\mathrm{Rh}(\mathrm{I})$ of $\operatorname{Ir}(\mathrm{I}))$, toon dat alle stukture wanordelik pak in die trikliniese ruimtegroep $P \overline{1}$ (Wilson et al., 2002, Kuwabara \& Bau, 1994, Churchill et al., 1994, Clarke et al., 2002, Grobbelaar et al., 2009). Dit blyk dus dat 'n moontlike bron vir die wanorde die wisselende steriese ruimtevereiste op die fosforsentrum kan wees, aangesien die Tolman-kegelhoekwaardes (bepaal deur CPK-modelle) vir $\mathrm{PPh}_{3}$ en $\mathrm{PCy}_{3}$ 'n groot reeks van $145^{\circ}$ tot $170^{\circ}$ beslaan. Om hierdie postulasie te toets, is Vaska-tipe komplekse van $\mathrm{Rh}(\mathrm{I})$ en $\operatorname{Ir}(\mathrm{I})$, saamgestel met fosfienligande met 'n steriese ruimtevereiste tussen $\mathrm{PPh}_{3}$ en $\mathrm{PCy}_{3}$, berei. Ten einde ander faktore wat ' $\mathrm{n}$ rol kan speel om die wanordepakking te verminder, is fosfienligande met mengsels van feniel- en sikloheksiel substituente gebruik. In hierdie bydrae word die strukture van $\mathrm{Rh}(\mathrm{I})$ en $\operatorname{Ir}(\mathrm{I})$ Vaska-tipe komplekse wat die fosfiene $\mathrm{PPh}_{2} \mathrm{Cy}$ en $\mathrm{PPhCy}{ }_{2}$ bevat, asook 'n omvattende ondersoek om die oorsprong van die $\mathrm{Cl}-\mathrm{M}-\mathrm{CO}$ wanorde vas te pen, gerapporteer.

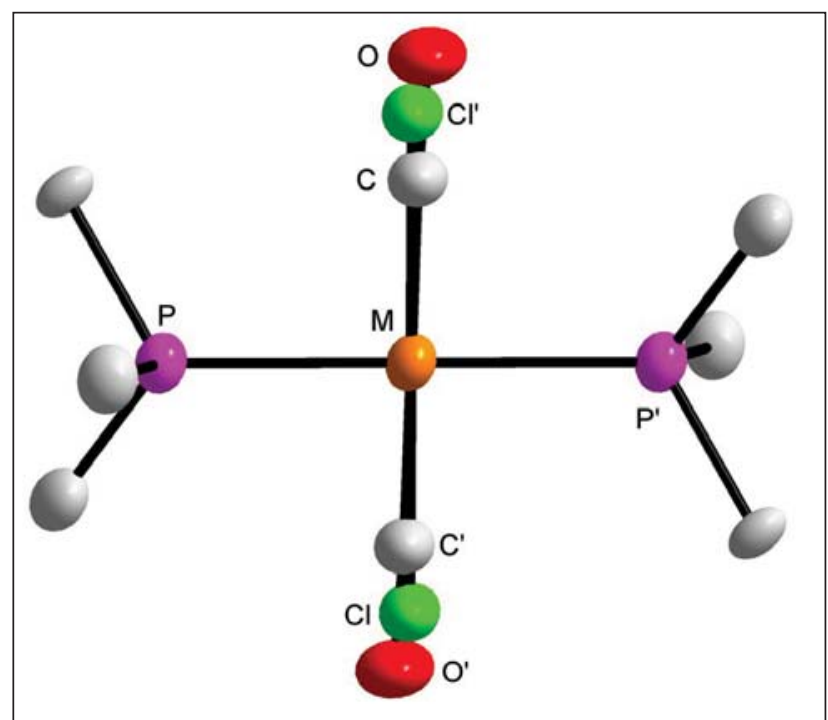

FIGUUR 1: 'n Vereenvoudigde struktuurvoorstelling van die $\mathrm{Cl}-\mathrm{M}-\mathrm{CO}$ wanorde wat in X-straalstrukture van Vaska-tipe komplekse voorkom. Aksentletters dui op atome wat gegenereer word deur kristallografiese simmetriebewerking- in hierdie geval ' $n$ inversiesentrum. 


\section{Materiale en metodes}

\section{Chemikalieë en instrumentasie}

Asetoon, etanol, metanol, dichlorometaan, heksaan, fosforpentoksied, difenielsikloheksiel-fosfien $\left(\mathrm{PPh}_{2} \mathrm{Cy}\right)$, fenieldisikloheksielfosfien $\left(\mathrm{PPhCy}_{2}\right)$, hidrokinoon, cis,cis-1,5-siklooktadiëen (almal van Sigma-Aldrich), $\mathrm{RhCl}_{3} \cdot \mathrm{xH}_{2} \mathrm{O}$ en $\mathrm{H}_{2} \mathrm{IrCl}_{6} \cdot 6 \mathrm{H}_{2} \mathrm{O}$ (almal van Next Chimica) is gebruik soos ontvang. KMR-spektra is op ' $\mathrm{n}$ Varian Inova $300 \mathrm{MHz}$ spektrometer $\left({ }^{1} \mathrm{H}: \quad 300 \mathrm{MHz},{ }^{31} \mathrm{P}: 121.46 \mathrm{MHz}\right)$ by kamertemperatuur versamel en onderskeidelik gekalibreer op die oorgeblewe geprotoneerde onsuiwerhede in die $\mathrm{CDCl}_{3}$ oplosmiddel $\left(\mathrm{CHCl}_{3}=7.24 \mathrm{dpm}\right)$ en 'n verseëlde kapillêr is gebruik wat $85 \% \mathrm{H}_{3} \mathrm{PO}_{4}$ bevat as nul dpm. ${ }^{31} \mathrm{P}-\mathrm{KMR}$ spektra is proton ontkoppel. Infrarooispektra is versamel op 'n Bruker Equinox 55 FT-IR spektrometer en geanaliseer met Bruker se OPUS-NT sagteware. Die $v(\mathrm{CO})$

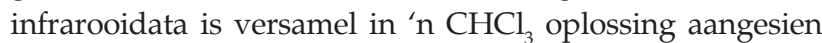
kristalpakkingseffekte, wat moontlik by die M-CO-binding geïnduseer kan word, aangetoon het om ' $\mathrm{n}$ beduidende invloed op die waardes te kan veroorsaak (Kemp et al., 1995). Dit maak vastetoestandmetings gevolglik onbetroubaar en daarom is infrarooidata vir oplossingspektra versamel met behulp van ' $\mathrm{n} \mathrm{NaCl}$-vloeistofsel (optiese padlengte $0.1 \mathrm{~mm}$ ).

Enkelkristaldata is op ' $\mathrm{n}$ Bruker SMART-stelsel versamel met 'n 1K CCD kamera en Mo K $\alpha$ ( $\lambda 0.71073 \AA$ A ) straling. Alle dataversamelings is by kamertemperatuur gedoen. Data is versamel met behulp van die SMART (Bruker, 1998) programstelsel met $\omega$-skanderings, selverfyning en dataherleiding is met SAINT-Plus en XPREP (Bruker, 1999) gedoen. Alle strukture is opgelos met behulp van die SIR97 (Altomare, et al., 1999) pakket, terwyl molekulêre beelde met DIAMOND (Brandenburg \& Berndt, 2001) voorberei is. Meervoudige skanderingabsorpsietegnieke is toegepas op alle data met behulp van SADABS (Bruker, 1998) en alle data is verfyn deur gebruik van volle matrikskwadrate op $\mathrm{F}^{2}$. Die aromatiese, metaan- en metileen $\mathrm{H}$-atome is in geometries-geïdealiseerde posisies $(\mathrm{C}-\mathrm{H}=$ 0.97-0.98) geplaas en verplig om op hul ooreenstemmende oueratome met $\mathrm{U}_{\text {iso }}(\mathrm{H})=1.2 \mathrm{U}_{\mathrm{eq}}(\mathrm{C})$ te beweeg. Wanorde van die $\mathrm{Cl}-\mathrm{M}-\mathrm{CO}$-groep is sonder enige geometriese beperkings verfyn terwyl die wanorde van die fenielen sikloheksielsubstituente hanteer is deur verfyning van twee posisies vir elke komponent met geometriese beperkings (SAME, FLAT, SIMU en DELU) waar dit nodig is om verfynings stabiel te hou. Daar is verseker dat die som van alle breuke van wanordelike atoomposisies tot heelgetalle lei wanneer dit bymekaar getel word. Alle data is nagegaan vir ontbinding deur die eerste 50 rame weer te versamel ná die volledige data-insameling. Ontbinding was onbeduidend binne die eksperimentele fout vir alle data. Aanlyn checkCIF resultate het geen ernstige waarskuwingsvlak A probleme aangedui vir geeneen van die datastelle nie, behalwe vir trans-[Rh(CO) $\left.\mathrm{Cl}\left(\mathrm{PPh}_{2} \mathrm{Cy}\right)_{2}\right]$ wat drie waarskuwingsvlak $\mathrm{B}$ probleme getoon het, moontlik as gevolg van swak hoëhoekdata. Dit is onbehandeld gelaat, aangesien die data voldoende blyk te wees vir die verfyning van alle wanorde in die molekule. Vir die bepaling van die steriese vereistes is die kristallografiese keëlhoeke bereken met Steric (Taverner, 1996). Aanpassings van die Tolman-keëlhoekmodel (Tolman, 1977) is gemaak deur die oriëntering van die substituente te neem uit kristallografiese data (in plaas van 'n CPK-model), en die M-PR bindingsafstand aan te pas na $2.28 \AA$ (om enige invloed wat hierdie variasie op die kegelgrootte kan hê, te normaliseer) (Müller \& Mingos, 1995, Otto et al., 2000). Aangesien die meeste dele van die fosfienligande wat hier bestudeer word, wanorde toon, is die gemiddelde waardes geneem vir beide komponente se berekeninge. Aanvullende data wat volledige lyste van atoomkoördinate, anisotropiese verplasingsparameters, bindingsafstande en -hoeke sowel as waterstofkoördinate bevat, word verskaf.

DFT-berekenings is uitgevoer op die $\mathrm{Rh}$ Vaska-tipe komplekse van $\mathrm{PPh}_{2} \mathrm{Cy}$ en $\mathrm{PPhCy}_{2}$ deur die Gaussian03 (Frisch et al., 2004) pakket te gebruik om meer insig te verkry in die geometriese konformasies van die bereide komplekse. Verskeie beginstrukture is geïdentifiseer weens die wanorde wat teenwoordig is en in elke geval noukeurig ondersoek om duplisering te vermy. Hierdie aanvangstrukture is sonder beperkinge geoptimaliseer op 'n B3LYP/LanL2DZ teorievlak. Minima is bevestig via frekwensie-analise van die stilstaande punt. Topologiese analise van die golffunksies vir die vrye fosfienreeks $\mathrm{PPh}_{2} \mathrm{Cy}$ en $\mathrm{PPhCy}_{2}$ is met behulp van Gaussian03 uitgevoer om 'n elektrostatiese potensiaal kubuslêer van die geoptimaliseerde geometrie (B3LYP/6-31G(d,p)) te verkry. Daarenteen is Vesta (Momma \& Izumi, 2011) gebruik om die potensiële oppervlak van die kubuslêer te visualiseer waarvan 'n rowwe voorspelling van die negatiewe potensiële oppervlak verkry word, en Univis 2000 (Limaye \& Gadre, 2001) om twee koördinate van hierdie oppervlak te kies. Hierdie oppervlakkoördinate is dan in Gaussian03 ingevoeg om die geoptimaliseerde waardes vir $\mathrm{V}_{\text {min }}$ te bereken.

\section{Algemene sintese}

Verskeie sinteseroetes vir Vaska-tipe komplekse van $\mathrm{Rh}(\mathrm{I})$ en $\operatorname{Ir}(\mathrm{I})$ bestaan. Vir rhodium was die metode wat hier verkies is sublimasie van die $\left[\mathrm{Rh}(\mathrm{Cl})(\mathrm{CO})_{2}\right]_{2}$ dimeer vanaf die $\mathrm{RhCl}_{3} \cdot \mathrm{xH}_{2} \mathrm{O}$ sout onder 'n koolstofmonoksied atmosfeer (McCleverty et al., 1990). Die $\left[\mathrm{Rh}(\mathrm{Cl})(\mathrm{CO})_{2}\right]_{2}$ dimeer is relatief stabiel en kan vir 'n paar jaar gestoor word met slegs geringe sublimasie wat voorkom. Die Vaska-tipe komplekse kan maklik daaruit berei word deur eenvoudige stoichiometriese byvoeging van die fosfien by kamertemperatuur in ' $\mathrm{n}$ geskikte oplosmiddel. Vir die Ir Vaska komplekse kan feitlik enige chloriedsout van iridium verhit word met ' $\mathrm{n}$ fosfien en koolstofmonoksiedbron. Vir die huidige studie is $\left[\mathrm{Ir}(\mathrm{Cl})(\operatorname{cod})_{2}\right]_{2}$ dimeer eers berei vanaf die $\mathrm{H}_{2} \mathrm{IrCl}_{6}$. $\mathrm{xH}_{2} \mathrm{O}$ sout (Bezman et al., 1980). Hierdie dimeer is ook stabiel en maak voorsiening vir sintese van die Ir Vaska-tipe verbindings by kamertemperatuur. Die prosedure vir die bereiding van Ir Vaska-tipe verbindings 
uit die dimeer is ietwat anders as dié van die Rh-analoog; hier word die steriese grootte van die fosfienligand eers in ag geneem. Soos beskryf deur Burk \& Crabtree, 1986, is wanneer die fosfienligand 'n klein Tolman-kegelhoek het, die cod ligande eers vervang deur CO gas deur 'n oplossing te borrel wat die dimeer bevat. Dit word dan gevolg deur die fosfien by te voeg wat die gewenste produk lewer. Vir groter fosfiene word hierdie volgorde omgekeer, d.i. die fosfienligand word eerste bygevoeg en dan gevolg deur borreling van $\mathrm{CO}$ gas. In die huidige geval het laasgenoemde die beste resultate vir die Ir Vaska-komplekse gelewer. Vir beide $\mathrm{Rh}$ en Ir Vaska-tipe komplekse is kristalle geskik vir enkelkristal $X$-straal data-insameling direk vanaf die reaksiemengsel verkry. Gedetailleerde eksperimentele prosedures en analitiese data van die voorlopers en produkte word in die aanvullende materiaal verskaf.

\section{Resultate en bespreking}

Kristaldata, besonderhede van die data-insameling en verfyning parameters vir trans- $\left[\mathrm{MCl}(\mathrm{CO})\left(\mathrm{PPh}_{2} \mathrm{Cy}\right)_{2}\right]$ $(\mathrm{M}=\mathrm{Rh}(\mathbf{1}), \mathrm{Ir}(3))$ en $\left[\mathrm{MCl}(\mathrm{CO})\left(\mathrm{PPhCy}_{2}\right)_{2}\right](\mathrm{M}=\mathrm{Rh}(2)$, Ir (4)) word opgesom in Tabel 1. Aangesien die molekulêre diagramme vir $\mathbf{1}$ en $\mathbf{3}$ feitlik dieselfde is, en so ook dié van 2 en 4, word slegs 1 en 2 in Figuur 2 aangetoon. Vir strukturele vergelyking met literatuur is die data van die isomorfe trans- $\left[\mathrm{MCl}(\mathrm{CO})\left(\mathrm{PX}_{3}\right)_{2}\right](\mathrm{M}=\mathrm{Rh}, \mathrm{Ir} ; \mathrm{X}=\mathrm{Ph}, \mathrm{Cy})$ van
Chen et al., 1991 en Wilson et al. 2002 (vir Rh-PPh $/ \mathrm{PCy}_{3}$ komplekse) en Churchill et al., 1994 en Kuwabara \& Bau, 1994 (vir Ir-PPh ${ }_{3} / \mathrm{PCy}_{3}$ komplekse) gebruik om moontlike kristalpakkingseffekte vanaf verskillende ruimtegroepe uit te skakel. Dis belangrik om daarop te let dat alle dataopnames, hier en soos gerapporteer, by kamertemperatuur versamel is, wat dan ook enige temperatuureffekte uitskakel ${ }^{1}$. Die besluit vir die versameling van $\mathrm{X}$-straaldata by kamertemperatuur vir $\mathbf{1}-\mathbf{4}$ is ook ondersteun deur die feit dat al die wanorde teëgekom met relatiewe gemak opgelos kon word. Daarbenewens is verwag dat die toename in meetkundige akkuraatheid verkry uit die dataversameling by laer temperatuur soortgelyke neigings sou openbaar as wat reeds vir die datastelle vir kamertemperatuur waargeneem is. Die moontlikheid van polimorfe kristalisering by lae temperature is ook uit die weg geruim. Die kristalstrukture van 1 tot 4 toon dat die molekule op ' $n$ kristallografiese inversiepunt van simmetrie geleë is wat ' $n 50 \%$ statistiese wanorde op die $\mathrm{Cl}-\mathrm{Rh}-\mathrm{CO}$-groep vereis. 'n Aanvanklike aaname was dat nie die elektroniese effek of die steriese grootte wat deur die fosfienligande geïndusieer word, enige effek op die uitkoms van die $\mathrm{Cl}-\mathrm{M}-\mathrm{CO}$ wanorde sou hê nie. Nadere ondersoek van die komplekse openbaar egter verskeie aspekte wat kan aandui waarom wanorde voorkom.

TABEL 1: Kristallografiese data-insameling en verfyning parameters vir komplekse trans-[MCl(CO)(PPh $\left.\left.\mathrm{Cy}_{3-n}\right)_{2}\right](\mathrm{M}=\mathrm{Ir}, \mathrm{Rh} ; \mathrm{n}=1,2)$ * $^{*}$

\begin{tabular}{|c|c|c|c|c|}
\hline Identifikasie kode ${ }^{a}$ & $\begin{array}{c}\mathrm{RhPh}_{2} \mathrm{Cy} \\
\text { (1) }\end{array}$ & $\begin{array}{l}\mathrm{RhPhCy}_{2} \\
\text { (2) }\end{array}$ & $\begin{array}{c}\mathrm{IrPh}_{2} \mathrm{Cy} \\
(\mathbf{3})\end{array}$ & $\begin{array}{l}\mathrm{IrPhCy} \\
\text { (4) }\end{array}$ \\
\hline 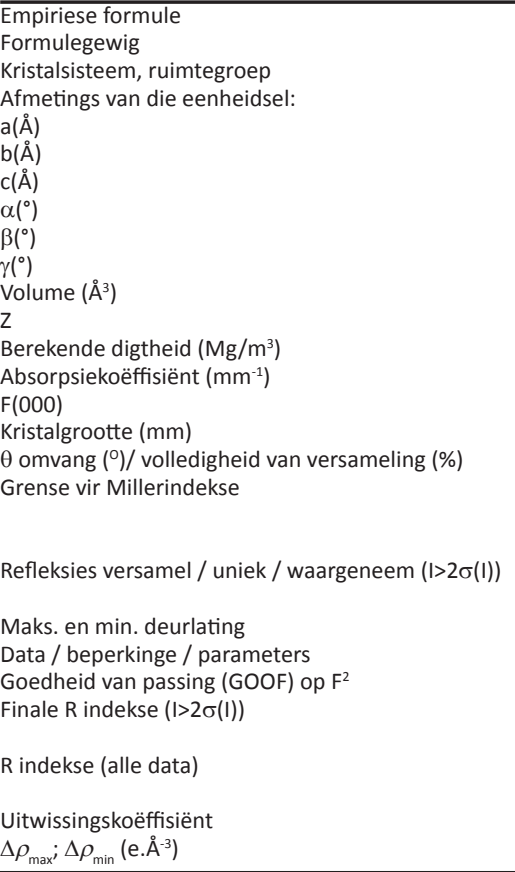 & $\begin{array}{c}\mathrm{C}_{37} \mathrm{H}_{42} \mathrm{ClOP}_{2} \mathrm{Rh} \\
703.01 \\
\text { Triklien, } P \mathrm{I} \\
\text { 9.469(13) } \\
10.129(19) \\
10.826(13) \\
116.25(2) \\
105.83(2) \\
92.66(3) \\
879(2) \\
1 \\
1.328 \\
0.68 \\
364 \\
0.40 \times 0.25 \times 0.10 \\
2.2-28.0 / 99.7 \\
-12 \leq \mathrm{h} \leq 12 \\
-13 \leq \mathrm{k} \leq 12 \\
-14 \leq 1 \leq 14 \\
7511 / 4229 / 3361 \\
\mathrm{R}(\mathrm{int})=0.1829 \\
0.9352-0.7727 \\
4229 / 343 / 315 \\
1.149 \\
\mathrm{R} 1=0.0505 \\
\mathrm{wR2}=0.1177 \\
\mathrm{R} 1=0.0754 \\
\mathrm{wR} 2=0.1567 \\
0.015(3) \\
1.230 \text { en }-1.450\end{array}$ & $\begin{array}{c}\mathrm{C}_{37} \mathrm{H}_{54} \mathrm{ClOP}_{2} \mathrm{Rh} \\
715.10 \\
\text { Triklien, } P^{\overline{1}} \\
9.4969(19) \\
10.211(2) \\
10.886(2) \\
113.69(3) \\
107.27(3) \\
91.41(3) \\
910.5(3) \\
1 \\
1.304 \\
0.657 \\
376 \\
0.26 \times 0.14 \times 0.13 \\
2.2-27.5 / 97.7 \\
-12 \leq \mathrm{h} \leq 12 \\
-12 \leq \mathrm{k} \leq 13 \\
-14 \leq \mathrm{I} \leq 9 \\
6016 / 4085 / 3613 \\
\mathrm{R}(\mathrm{int})=0.0177 \\
0.9195-0.8478 \\
4085 / 314 / 314 \\
1.06 \\
\mathrm{R} 1=0.0305 \\
\mathrm{wR2}=0.0664 \\
\mathrm{R} 1=0.0382 \\
\mathrm{wR2}=0.0696 \\
- \\
0.282 \text { en }-0.329\end{array}$ & $\begin{array}{c}\mathrm{C}_{37} \mathrm{H}_{42} \mathrm{CllrOP}_{2} \\
792.30 \\
\text { Triklien, Pi } \\
9.4689(19) \\
10.062(2) \\
10.878(2) \\
116.58(3) \\
105.98(3) \\
92.49(3) \\
874.2(3) \\
1 \\
1.505 \\
4.013 \\
396 \\
0.13 \times 0.10 \times 0.08 \\
2.2-28.0 / 99.7 \\
-6 \leq \mathrm{h} \leq 12 \\
-13 \leq \mathrm{k} \leq 13 \\
-14 \leq \mathrm{I} \leq 14 \\
7600 / 4214 / 3509 \\
\mathrm{R}(\text { int })=0.0394 \\
0.7396-0.6235 \\
4214 / 383 / 314 \\
1.026 \\
\mathrm{R} 1=0.0452 \\
\mathrm{wR2}=0.0872 \\
\mathrm{R} 1=0.0631 \\
\mathrm{wR2}=0.0950 \\
- \\
1.623 \text { en }-0.545\end{array}$ & 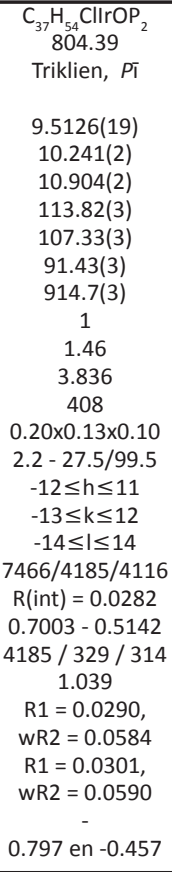 \\
\hline
\end{tabular}

* Die gegewens vir die vier kristalstrukture is in die Cambridge kristallografiese databasis met verwysingsnommers: CCDC 1949313 - 1949316 gelaai en is gratis op aanvraag beskikbaar.

Identifikasiekodes vir enkelkristalstrukture: $\mathrm{RhPh}_{2} \mathrm{Cy}=$ trans-[RhCl$\left.(\mathrm{CO})\left(\mathrm{PPh}_{2} \mathrm{Cy}\right)_{2}\right], \mathrm{RhPhCy}_{2}=\operatorname{trans}_{-}\left[\mathrm{RhCl}(\mathrm{CO})(\mathrm{PPhCy})_{2}\right], \operatorname{IrPh} \mathrm{Cy}_{2}=\operatorname{trans}-\left[\mathrm{IrCl}(\mathrm{CO})\left(\mathrm{PPh} \mathrm{Cy}_{2}\right], \mathrm{IrPhCy}{ }_{2}\right.$ $=$ trans $-\left[\mathrm{IrCl}(\mathrm{CO})\left(\mathrm{PPhCy}_{2}\right)_{2}\right]$.

1. Vgl. Ir-Cl afstande in trans-[IrCl(CO)(PPh $\left.)_{2}\right]$ is 2.382(3) ̊ vs. 2.306(8) Å vir die monokliniese (Blake et al., 1991) en trikliniese (Churchill et al., 1988) polimorfe. So ook, vgl. die kleiner variasie in Ir-C afstande in trans-[IrCl(CO)(PCy $\left.)_{2}\right]$ as $1.127(10) \AA ̊$ vs. $1.10(2) \AA ̊$ vir data wat onderskeidelik by kamertemperatuur versamel is (Kuwabara \& Bau, 1994) en $100 \mathrm{~K}$ (Grobbelaar et al., 2009). 


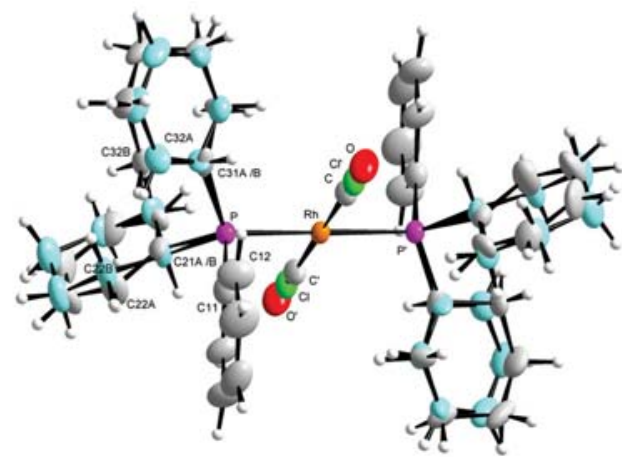

1

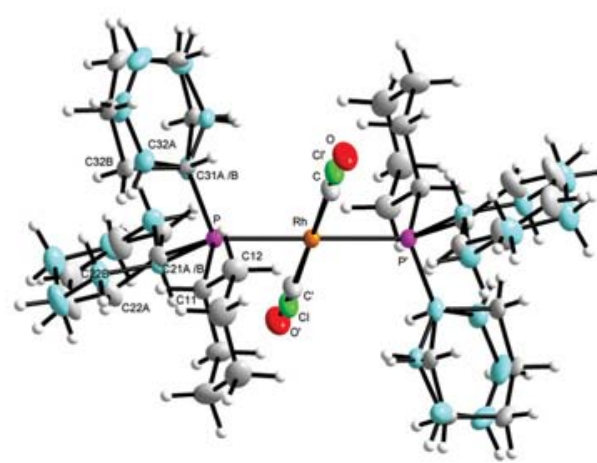

2

FIGUUR 2: Molekulêre diagram wat die nommeringskema en ellipsoïede verplaas ( $30 \%$ waarskynlikheid) vir $\mathbf{1}$ en $\mathbf{2}$ toon. Nommeringskema van die C-ringe: eerste syfer dui die ringnommer aan; tweede syfer dui die nommer van die atoom in die ring aan; $A / B$ dui onderskeidelik wanorde aan in feniel- of sikloheksielgroepe. Verskillende wanorde dele wat bymekaar hoort is ligblou of grys gekleur. Aksentletters is gebruik op atome wat gegenereer word deur simmetrie-werking $(1-x, 1-y, 1-z)$

Die aanvanklike verfyning van die strukture toon dat fenielringe van planariteit afwyk en sikloheksielringe neem nie heeltemal 'n stoelkonformasie aan nie. Termiese ellipsoïede vir sommige van die koolstofatome in hierdie ringe blyk ook groter te wees as gewoonlik en dui op wanorde (sien Figuur 3 as voorbeeld). In die geval van die $\mathrm{PPh}_{2} \mathrm{Cy}$ komplekse blyk dit dat een van die fenielringe minder verwring is, d.w.s. $<5^{\circ}$ afwyking van planariteit, terwyl in die geval van die $\mathrm{PPhCy}_{2}$ komplekse kan 'n soortgelyke waarneming gemaak word vir een van die sikloheksielringe, d.w.s. $<5^{\circ}$ afwyking van die ideale $60^{\circ}$ torsiehoeke wat gewoonlik waargeneem word vir 'n stoelkonformasie. As addisionele bewys vir die wanorde van hierdie ringe toon analitiese data dat elke fosfien suiwer is. Daar is besluit dat die enkelkristaldata ook hanteer moet word met wanordeverfynings van die fosfienligande.

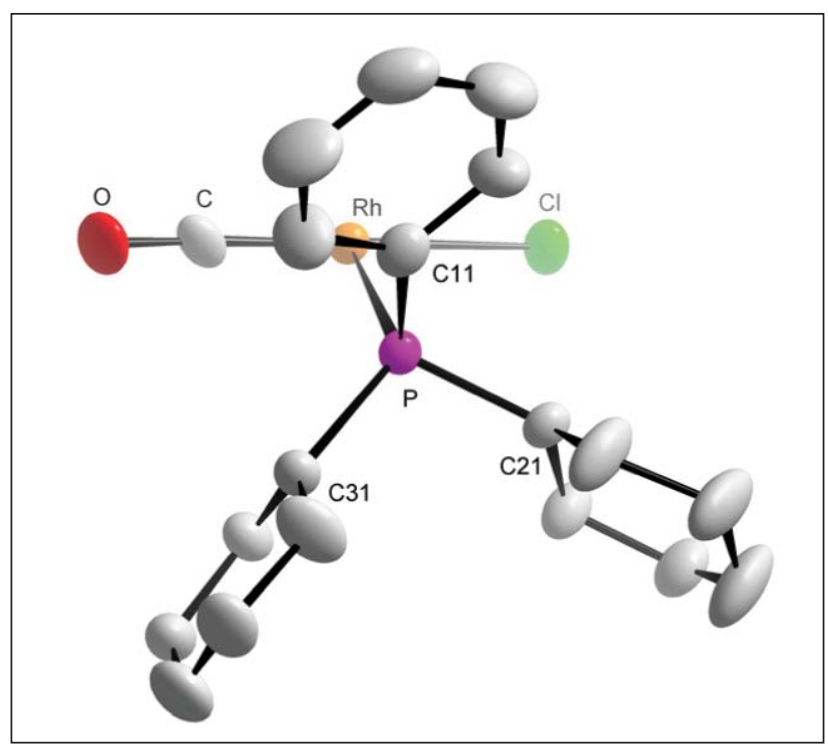

FIGUUR 3: Gedeeltelike molekulêre diagram wat verskillende ellipsoïde groottes toon ( $30 \%$ waarskynlikheid) vir koolstofatome van die $\mathrm{PPh}_{2} \mathrm{Cy}$ fosfienligand tydens die aanvanklike verfyning van 1.
Pogings om 'n wanordemodel te verfyn oor al drie substituente van die fosfienligand was nie suksesvol nie (onstabiele, nie-konvergerende verfynings), en die besluit is geneem om voort te gaan met ' $n$ verfyningsmodel waar die wanorde aangespreek word met een stel feniel- en sikloheksielringe oormekaar geplaas. Die oorblywende feniel in $\mathrm{PPh}_{2} \mathrm{Cy}$ en die sikloheksiel in $\mathrm{PPhCy}_{2}$ (beide geen aanduiding van wanorde in pakking) is onbehandeld gelaat. Dit het gelei tot 'n aanvaarbare en stabiele verfyning van die fosfienligande soos aangedui in die voorbeeld wat in Figuur 4 geillustreer word.

Hierdie tipe wanorde van die feniel-sikloheksiel ringe oor twee van die substituente is skaars en word slegs gevind in 'n handvol van literatuurvoorbeelde uit die Cambridge kristallografiese databasis (Groom et al., 2016). ${ }^{2}$ Hierdie wanorde dui op gedeeltelike vryheid vir volledige rotasie by die M-P binding en hoewel dit blyk dat die ruimte wat deur ' $\mathrm{n}$ feniel opgeneem word vergelykbaar is met dié van 'n sikloheksiel, is dit nie heeltemal die geval nie. Gegewe dat die kristalstrukture in die reeks trans- $\left[\mathrm{MCl}(\mathrm{CO})(\mathrm{L})_{2}\right](\mathrm{M}$

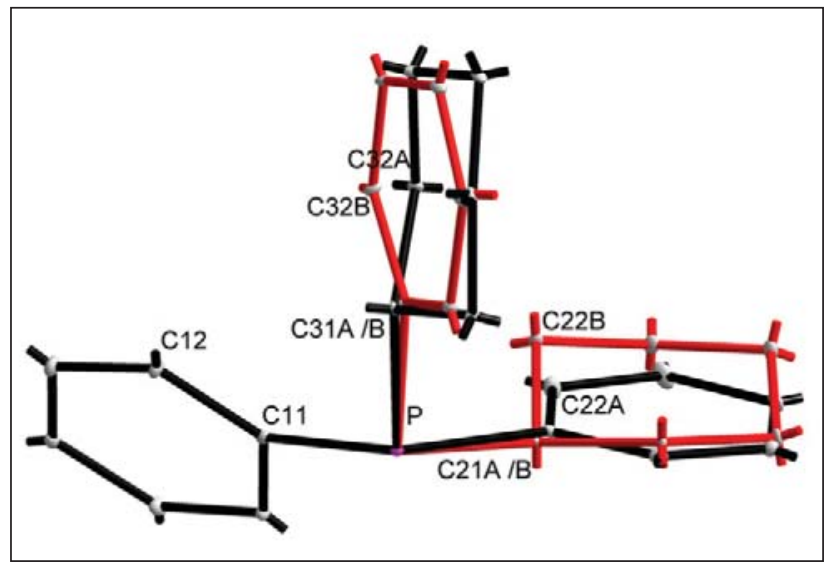

FIGUUR 4: Gedeeltelike draadraamdiagram van 1 (slegs fosfien) wat die wanorde tussen ' $n$ feniel en sikloheksiel toon. Vir groter duidelikheid word die tweede komponent van die afwyking in rooi geilllustreer. 2. $\mathrm{n}$ Soektog in die databasis na PPh $\mathrm{Py}_{2}$ word 55 strukture gevind met slegs 2 wat dieselfde wanorde toon soos hier bespreek. Vir PPhCy 2 is daar 48 voorbeelde met 6 van
hierdie wat die wanorde toon. 
$=\mathrm{Rh}, \mathrm{Ir} ; \mathrm{L}=\mathrm{PPh}_{3}, \mathrm{PPh}_{2} \mathrm{Cy}, \mathrm{PPhCy}_{2}, \mathrm{PCy}_{3}$ ) isomorf is (sien eenheidselafmetings in Tabel 1), toon ' $n$ vergelyking van die eenheidselvolumes in Tabel 2 'n konstante toename in eenheidselvolume (ongeveer $40 \AA^{3}$ vir elke feniel vervang met 'n sikloheksiel) in die reeks. Dit illustreer die groottefaktor van sikloheksiel duidelik soos dit stapsgewys in die reeks opgeneem word. Dit is ook interessant om daarop te let dat die besettingverspreiding tussen fenielen sikloheksielwanorde nie gelyk is nie, met die $\operatorname{Ir}(\mathrm{I})$ Vaska-tipe strukture wat die skewe verdeling van 60:40 toon; ' $n$ waarneming wat moontlik gekoppel kan word aan die effense toename in grootte en reaktiwiteit van laasgenoemde metaal.

TABEL 2: Eenheidselvolumes van Vaska-tipe komplekse met formule trans$\left[\mathrm{MCl}(\mathrm{CO})(\mathrm{L})_{2}\right]\left(\mathrm{M}=\mathrm{Rh}, \mathrm{Ir} ; \mathrm{L}=\mathrm{PPh}_{3}, \mathrm{PPh}_{2} \mathrm{Cy}, \mathrm{PPhCy}_{2}, \mathrm{PCy}_{3}\right)$.

\begin{tabular}{l|c|c}
\hline (L) & $\mathrm{Rh}$ & $\mathrm{Ir}$ \\
\hline $\mathrm{PPh}_{3}$ & $815.721^{\mathrm{a}}$ & $824.174^{\mathrm{b}}$ \\
$\mathrm{PPh}_{2} \mathrm{Cy}$ & $879(2)$ & $874.2(3)$ \\
$\mathrm{PPhCy}_{2}$ & $910.5(3)$ & $914.7(3)$ \\
$\mathrm{PCy}_{2}$ & $935.549^{\mathrm{c}}$ & $935.983^{\mathrm{d}}$ \\
\hline
\end{tabular}

${ }^{a}$ Chen et al., 1991; ${ }^{b}$ Wilson et al., 2002; c Wilson et al., 2002; ${ }^{\text {d } ~ K u w a b a r a ~ \& ~}$ Bau, 1994

By nadere ondersoek van die geometriese data van die metaalkoördinasiesfeer is ' $n$ gerieflike metode vir vergelyking tussen die koördinasie-omgewings van 1 -4, die berekening van die verplasing van die metaal uit die vlak wat deur die koördinerende atome gevorm word. In die huidige studie word die metaal verplaas 00012(5), $0.001(3),-0.045(8)$ en $-0.002(5) \AA$ bo of onder 'n vlak wat onderskeidelik deur die vier donoratome in $\mathbf{1}$ tot 4 gevorm word. Soortgelyke waarnemings kan gemaak word vir die $\mathrm{PPh}_{3}$ - en $\mathrm{PCy}_{3}$ analoë van $\mathrm{Rh}$ en Ir Vaskatipe sisteme. Daarbenewens word geringe vervormings in geometriese hoeke (P-M-P, Cl-M-C en C/Cl-M-P) by die metaalkoördineringsfeer waargeneem (byna alle hoeke toon afwykings van minder as $3^{\circ}$ van ideale geometrieë). Dit lei tot die gevolgtrekking dat die verwringings by die metaalkern klein is.

Alkielgesubstitueerde fosfienligande, bv. $\mathrm{PCy}_{3^{\prime}}$ word beskou as sterk basisse en dus goeie $\sigma$-skenker ligande. Hulle is egter ook swak $\pi$-suur van aard en die binding word dus nie beduidend versterk deur terugskenking in die $\sigma^{*}$ orbitaal van fosfor nie. In die huidige geval, waar feniel stapsgewys vervang word met sikloheksiel, word verwag dat M-P bindings geleidelik verleng sal word. Literatuurvoorbeelde om bogenoemde stelling te ondersteun sluit in werk gedoen op Taft en Hammet parameters wat verband hou met berekende $\mathrm{p} K_{\mathrm{a}}$ waardes van $\mathrm{PPh}_{3}$ vs. $\mathrm{PCy}_{3}$ (Allman \& Goel, 1982), kinetiese metings wat ' $\mathrm{n}$ toename in die tempo van oksidatiewe addisie van $\mathrm{KSeCN}$ tot fosfien toon met ' $\mathrm{n}$ toenemende aantal sikloheksielsubstituente (Muller et al., 2008), sowel as 'n analoog $\mathrm{R}=\mathrm{Ph} / \mathrm{Cy}$ stelsel, nl. $\mathrm{SeP}\left(\mathrm{p}-\mathrm{NMe}_{2}-\mathrm{C}_{6} \mathrm{H}_{4}\right) \mathrm{R}_{2}$ (Davis \& Muller, 2012, Phasha et al., 2012). Daarbenewens word verwag dat die CO-binding, alhoewel cis ten opsigte van $\mathrm{M}-\mathrm{P}$ rigting, geleidelik verswak sal word as gevolg van verhoogde $\pi$-terugskenking $\left(\pi^{*} \rightarrow \mathrm{d}\right)$ in die $\mathrm{M}-\mathrm{C}$ binding. Waardes vir bindingsafstande in Tabel 3 is aanduidend hiervan, maar afwyking vir die $\mathrm{PPh}_{2} \mathrm{Cy}$ ligand oor die Rh-reeks, en in mindere mate by die Ir-komplekse, word waargeneem.

'n Verdere interessantheid is om daarop te let dat die berekende kristallografiese keëlhoeke 'n verskil toon vir hierdie spesifieke ligand: die waarde vir beide $\mathrm{Rh}$ en Ir$\mathrm{PPh}_{2} \mathrm{Cy}$ Vaska-tipe komplekse is aansienlik kleiner as dié van $\mathrm{PPh}_{3}$ ! Dit is te verwagte dat die keëlhoek stelselmatig sal vergroot met die opeenvolgende vervanging van feniel deur sikloheksiel, soos met die Tolman-keëlhoeke vanaf die geïdealiseerde CPK-model $\left(145^{\circ}, 153^{\circ}, 161^{\circ}, 170^{\circ}\right.$ vir $\mathrm{PPh}_{3}, \mathrm{PPh}_{2} \mathrm{Cy}, \mathrm{PPhCy}_{2}$ en $\mathrm{PCy}_{3}$ onderskeidelik). Die gebruik van kristallografiese keëlhoeke neem egter die werklike fosfienligandomgewings in ag en as gevolg hiervan is dit ' $n$ beter aanduiding van ligand se steriese gedrag. Alhoewel bogenoemde vastetoestandmetings is, is die gedrag van die komplekse in die vloeistoffase ook nie ideaal nie: Die ${ }^{1} J_{\text {Rh-P }}$ (vanaf ${ }^{31} \mathrm{P}\left\{{ }^{1} \mathrm{H}\right\} \mathrm{KMR}$ ) en $\mathrm{v}(\mathrm{CO})$ waardes (in droë $\mathrm{CHCl}_{3}$ ) vir $\mathrm{Rh}$ Vaska-tipe komplekse van $\mathrm{PPh}_{2} \mathrm{Cy}$ en $\mathrm{PPhCy}_{2}$ toon feitlik geen verskil in byna alle gevalle nie. 'n Moontlike verduideliking vir hierdie waarnemings kan gevind word in die ondersoek van $\mathrm{M}-\mathrm{P}-\mathrm{C}_{\text {ipso }}$ bindingshoeke. Vir $\mathrm{Rh}(\mathrm{I})$ en $\mathrm{Ir}(\mathrm{I})$ Vaska-tipe komplekse van $\mathrm{PPh}_{3}, \mathrm{PPhCy}_{2}$ en $\mathrm{PCy}_{3}$ is hierdie hoeke minstens $110^{\circ}$ of hoër. In die geval van die $\mathrm{Rh}(\mathrm{I})$ en $\mathrm{Ir}(\mathrm{I})$ Vaska-tipe komplekse van $\mathrm{PPh}_{2} \mathrm{Cy}$, word egter 'n kleiner as $110^{\circ}$ hoek waargeneem vir die niewanordelik gepakte feniel. 'n Moontlike rede vir hierdie verskil is eerstens dat die versteurde feniel- en sikloheksielsubstituentkombinasies langs die $\mathrm{C}-\mathrm{M}-\mathrm{P}-\mathrm{C}_{\mathrm{ipso}}$ gedraai word sodat sikloheksiel en feniel mekaar se ruimte kan naboots

TABEL 3: Geselekteerde meetkundige parameters $\left(\AA \AA^{\circ}{ }^{\circ}\right.$ vir die verbindings met die algemene formule trans- $\left[\mathrm{MCl}(\mathrm{CO})(\mathrm{L})_{2}\right]$.

\begin{tabular}{|c|c|c|c|c|c|c|}
\hline$(\mathrm{M})(\mathrm{L})$ & $M-P$ & $\mathrm{M}-\mathrm{Cl}$ & $M-C$ & $\mathrm{C}-\mathrm{M}-\mathrm{Cl}$ & $\theta_{\mathrm{E}}$ & Ref \\
\hline$(\mathrm{Rh})\left(\mathrm{PPh}_{3}\right)$ & $2.3279(7)$ & $2.380(2)$ & $1.759(7)$ & $179.7(3)$ & 156 & Chen et al., 1991 \\
\hline$(\mathrm{Rh})\left(\mathrm{PPh}_{2} \mathrm{Cy}\right)$ & $2.308(2)$ & $2.369(5)$ & $1.741(15)$ & $178.3(5)$ & 150 & 1 \\
\hline$(\mathrm{Rh})\left(\mathrm{PPhCy}_{2}\right)$ & $2.3376(11)$ & $2.379(2)$ & $1.749(7)$ & $178.2(3)$ & 159 & 2 \\
\hline$(\mathrm{Rh})\left(\mathrm{PCy}_{3}\right)$ & $2.3508(3)$ & $2.3880(13)$ & $1.745(5)$ & $178.57(11)$ & 160 & Wilson et al., 2002 \\
\hline$(\operatorname{Ir})\left(\mathrm{PPh}_{3}\right)$ & $2.330(I)$ & $2.382(3)^{3}$ & $1.791(13)$ & $178.1(4)$ & 157 & Churchill et al., 1994 \\
\hline$(\mathrm{Ir})\left(\mathrm{PPh}_{2} \mathrm{Cy}\right)$ & $2.3327(16)$ & $2.330(6)$ & $1.65(2)$ & $174.8(9)$ & 149 & 3 \\
\hline$(\mathrm{Ir})\left(\mathrm{PPhCy}_{2}\right)$ & $2.3378(12)$ & $2.383(3)$ & $1.788(11)$ & $178.4(4)$ & 159 & 4 \\
\hline$(\mathrm{Ir})\left(\mathrm{PCy}_{3}\right)$ & $2.345(2)$ & $2.398(7)$ & $1.78(2)$ & $176.1(7)$ & 161 & Kuwabara \& Bau, 1994 \\
\hline
\end{tabular}

3. Soos vermeld in hierdie inskrywing van die Cambridge kristallografiese databasis, is die koördinate van die chloriedligand nie behou nie. In die oorspronklike artikel lui dit egter dat die $\mathrm{Cl}-\mathrm{Ir}-\mathrm{CO}-$ wanorde duidelik gedefinieër kan word, en dus kan meetkundige gegewens hier gerapporteer word. 
(sien Figuur 4). Hierdie is duidelik in die keëlhalwehoek wat bereken word vir die nie-versteurde fenielsubstituent wat minstens $6^{\circ}$ laer is as enige van die ander berekende halwehoeke. Tweedens toon die $\mathrm{C}_{\mathrm{ipso}}-\mathrm{H}$ van die niewanordelike sikloheksiel ook ' $\mathrm{n} \mathrm{C}-\mathrm{H} \cdots \mathrm{Cl}$ intramolekulêre interaksie (sien aanvullende materiaal) wat nie in $\mathrm{PPh}_{2} \mathrm{Cy}$ komplekse voorkom nie. Daar kan bespiegel word dat albei redes hierdie waarnemings veroorsaak dat die $\mathrm{PPh}_{2} \mathrm{Cy}$ ligand ' $n$ anders as verwagte kristallografiese keëlhoek het en dat sowel die orbitaaloorvleueling by die $\mathrm{C}_{\mathrm{ipso}}-\mathrm{P}$ binding afwykings veroorsaak wat nie te wagte was nie.

Ondersteuning van die bogenoemde waarnemings en argumente kom van die $\mathrm{SePPh}_{2} \mathrm{Cy}$ en $\mathrm{SePPhCy}$ verbindings van Muller et al., 2008, wat 'n fosforomgewing wat minder beperk is vir $\mathrm{PPh}_{2} \mathrm{Cy}$ aandui, aangesien die kristallografiese keëlhoekwaardes ongeveer dieselfde is vir die twee verbindings weens alle $\mathrm{C}_{\mathrm{ipso}}-\mathrm{P}-\mathrm{Se}$ hoeke wat vergelykbaar is $\left(175^{\circ}\right.$ vs. $\left.176^{\circ}\right)$. Hier blyk dit ook dat die orbitaaloorvleueling van $\mathrm{C}_{\mathrm{ipso}}-\mathrm{P}$ meer geloofwaardig is, aangesien die ${ }^{1} J_{\text {Se-p }}$ koppelingskonstantes in ${ }^{31} \mathrm{P}\left\{{ }^{1} \mathrm{H}\right\} \mathrm{KMR}$ beduidende verskille toon (724 vs. $701 \mathrm{~Hz})$.
Verder kan berekeningschemie ook gebruik word om aan te toon dat hierdie twee fosfiene wel elektronies verskil. Die metode wat ontwikkel is deur Suresh \& Koga, 2002, toon dat die berekening van die molekulêre elektrostatiese potensiaal minimum $\left(\mathrm{V}_{\text {min }}\right)$ gebruik kan word as direkte kwantitatiewe meeting van elektronskenkende krag van fosfiene in teenstelling met die indirekte metodes soos $v(\mathrm{CO})$ in metaalfosfienkomplekse waar ander ligande in die koördinasiesfeer hierdie parameter ook kan beïnvloed. Berekening van $\mathrm{V}_{\min }$-waardes vir die vrye fosfienreeks $\mathrm{PPh}_{3-\mathrm{n}} \mathrm{Cy}_{\mathrm{n}}, \mathrm{n}=0$ tot 3 toon geleidelik negatiewe waardes (wat ' $\mathrm{n}$ aanduiding is van meer elektronskenkende krag) van onderskeidelik -34.81, -38.15, -41.63 en -45.24. Dit toon dus ' $n$ meer progressiewe neiging vir hierdie reeks verbindings in teenstelling met dié in die Vaska-stelsels wat hier bestudeer is.

In wese toon bogenoemde bespreking oor die reeks $\mathrm{Rh} /$ Ir $\mathrm{PPh}_{3-\mathrm{n}} \mathrm{Cy}_{\mathrm{n}^{\prime}} \mathrm{n}=0$ tot 3, Vaska-tipe komplekse dat die gedrag van die feniel- en sikloheksielsubstituente blykbaar is om te probeer "aanpas" by die beskikbare spasie van die metaalkoördineringsomgewing, wat verskille

TABEL 4: Data verkry uit teoretiese optimalisering van die verskillende oriëntasies vir die verbindings trans-[RhCl(CO) $\left.\left.\left(\mathrm{PPh}_{2} \mathrm{Cy}\right)_{2}\right)_{2}\right]$ en trans-[RhCl(CO)(PPhCy$\left.)_{2}\right]$.

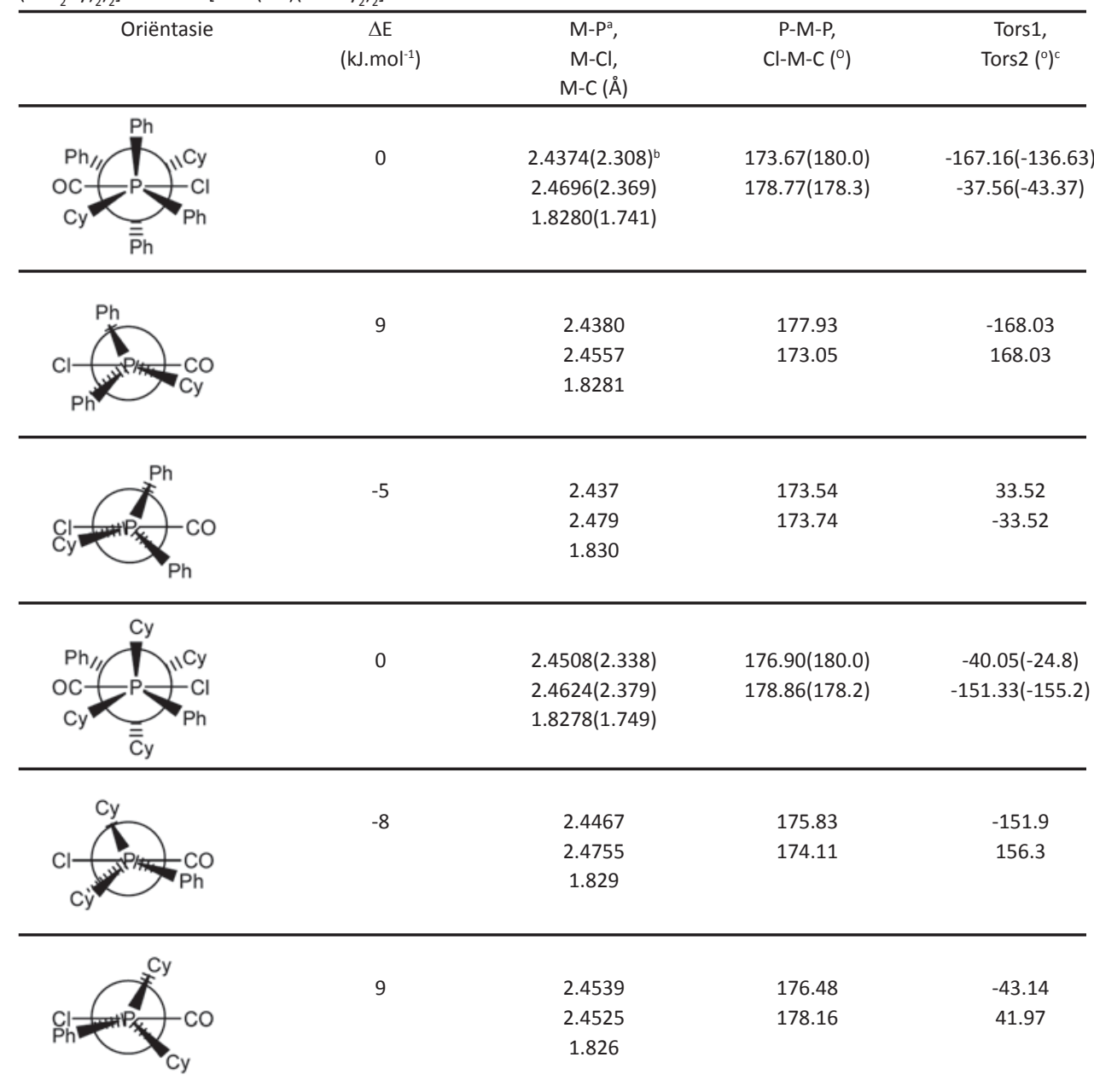

$\mathrm{a}=$ gemiddeld van die twee M-P-bindingsafstande; $\mathrm{b}=$ Waardes tussen hakies is geneem uit enkelkristal X-straaldata; $c$ $=$ Tors 1 , Tors2 $=$ torsiehoeke van onewe fosfiensubstituent van elke ligand $\mathrm{C}_{\mathrm{ipso}}-\mathrm{P}-\mathrm{Rh}-\mathrm{Cl}$. 
veroorsaak aan steriese en elektroniese parameters van die fosfienligande wat gebruik word. Dit blyk ook om geen effek te hê op die Cl-M-CO-groep wat 'n statistiese wanorde aanneem wat deur kristallografiese simmetrie beheer word nie.

Berekeningschemie is ook gebruik in 'n poging om die wanorde van die $\mathrm{Cl}-\mathrm{M}-\mathrm{CO}$ groep te voorspel. Uit die Cambridge kristallografiese databasis (Groom et al., 2016) blyk dit dat die Cl-M-CO wanorde verband hou met verskillende konformasies van die fosfiene sowel as hul relatiewe oriëntasie op die $\mathrm{Cl}-\mathrm{M}-\mathrm{CO}$-groep. As die fosfiensubstituente langs die $\mathrm{P}-\mathrm{M}-\mathrm{P}$ rigting gesteier is, is daar gewoonlik ' $\mathrm{n}$ wanorde in die $\mathrm{Cl}-\mathrm{M}-\mathrm{CO}$-groep, in teenstelling met verduisterde substituente, wanneer geen wanordelike $\mathrm{Cl}-\mathrm{M}-\mathrm{CO}$ groep gewoonlik waargeneem word nie. Daarbenewens blyk dit dat nie-wanordelike stelsels een substituent van elke fosfien amper in lyn is met die $\mathrm{M}-\mathrm{CO}$ binding, terwyl die wanordelike stelsel geen van die substituente toon in lyn met die vierkantigplanêre koördinasie-omgewing nie. Deur gebruik te maak van bogenoemde waarnemings, sou dit moontlik wees om relatiewe energieverskille tussen hierdie konformasies te bereken wat meer insig kan gee in die versteuring by die Cl-M-CO-groep. Daar moet egter ook op gelet word dat aangesien die $\mathrm{Cl}-\mathrm{M}-\mathrm{CO}$-groep wanorde kan toon, dit impliseer dat die opsie waar die $\mathrm{M}-\mathrm{Cl}$ met een van die substituente van beide fosfiene verduister, ook oorweeg word. Op grond van hierdie oorwegings is ' $n$ voorlopige berekeningstudie met slegs 'n relatief lae basisstel onderneem met $\mathbf{1}$ en $\mathbf{2}$. Konformasies is geoptimaliseer en energieë vergelyk, die resultate hiervan is in Tabel 4 opgesom.

Op hierdie teorievlak wat gebruik is vir die optimalisering, toon die resultate min variasie in die relatiewe energieverskil tussen gesteier en verduisterde konformasies, en is dit nie betroubaarom dieeksperimenteleuitkomsvankonformasies te voorspel nie. As beide verduisterde konformasies (vir $\mathrm{M}-\mathrm{CO}$ en $\mathrm{M}-\mathrm{Cl}$ ) vir elke fosfien in ag geneem word, kan die verskil tussen hulle egter as beduidend beskou word om nie hierdie konformasie aan te neem nie (vgl. $14 \mathrm{~kJ} /$ mol vir $\mathrm{PPh}_{2} \mathrm{Cy}$ en $17 \mathrm{~kJ} / \mathrm{mol}$ vir $\mathrm{PPhCy}_{2}$ ), maar eerder die gesteierde konformasie; laasgenoemde hou verband met die wanorde van die $\mathrm{Cl}-\mathrm{M}-\mathrm{CO}$-groep wat eksperimenteel in hierdie stelsels waargeneem word. Hierdie postulasie sal verder ondersoek moet word voordat dit aangeneem kan word as ' $\mathrm{n}$ metode om die wanorde van die $\mathrm{Cl}-\mathrm{M}-$ CO-groep te bepaal. Verder toon die vergelyking van meetkundige waardes tussen geoptimaliseerde en dié uit die eksperimentele kristalgegewens dat konformasies ietwat anders is, en dit kan aandui dat addisionele pakkingseffekte ' $n$ rol speel in die finale konstruksie wat in die vaste toestand waargeneem word.

\section{Slotsom}

Vaska-tipe sisteme van die algemene vorm trans-[M(CO) $\mathrm{Cl}\left(\mathrm{PPh}_{3-\mathrm{n}} \mathrm{Cy}_{\mathrm{n}}\right)_{2} \mathrm{l}$, waar $\mathrm{M}=\mathrm{Rh}$, Ir en $\mathrm{n}=0$ tot 3 toon dat die stapsgewyse vervanging van feniel met meer lywige en elektronskenkende sikloheksiel oënskynlik geen daadwerklike impak het op die statistiese $\mathrm{Cl}-\mathrm{M}-\mathrm{CO}$ wanorde waargeneem in die enkel kristal X-straalkristallografiese strukture van hierdie komplekse nie. Insig is verkry in die aard van die steriese en elektroniese eienskappe van $\mathrm{PPh}_{2} \mathrm{Cy}$ en $\mathrm{PPhCy}_{2}$ en toon aan dat dit maklik gemanipuleer kan word, afhangende van hul omgewings, veral in die geval van $\mathrm{PPh}_{2} \mathrm{Cy}$.

Resultate toon verder dat die fosfienligande oënskynlik poog om by hul omgewing aan te pas en in wese na 'n algemene steriese grootte te streef. Of die steriese grootte van die fosfienligand die afwyking sal beïnvloed as dit groot genoeg is, kan debateer word aangesien die enkelkristal X-straalstruktuur van trans- $[\mathrm{Rh}(\mathrm{CO}) \mathrm{Cl}\{\mathrm{P}(o-$ toliel) $\left.{ }_{3}\right\}_{2}$ ] (Warsink et al., 2011), met 'n baie groot Tolmankegelhoek van $194^{\circ}$, steeds wanorde toon in die Cl-Rh-COgroep terwyl die kristallografiese keëlhoek gemeet word as $169^{\circ}$. Dit blyk dus moeilik om die Cl-M-CO-groep wanorde slegs vanaf steriese ruimtevereiste van die fosfienligand te bepaal.

Die gebruik van berekeningschemie om hierdie wanorde te bepaal toon wel belofte, maar dit benodig ' $n$ meer uitgebreide studie op hoër vlakke van teorie voordat enige verdere gevolgtrekkings gemaak kan word.

\section{Erkennings}

Finansiële steun van die Sweedse Agentskap vir Internasionale Ontwikkelingssamewerking (SIDA), Sasol en die Universiteit van Johannesburg word met dank erken.

\section{Verwysings}

Bruker SMART-NT Version 5.050. (1998). Bruker AXS Inc. Area-Detector Software Package. Madison, WI, USA.

Allman T, Goel RG. (1982). The basicity of phosphines. Canadian Journal of Chemistry 60(6), 716-722.

Altomare A, Burla MC, Camalli M, Cascarano GL, Giacovazzo C, Guagliardi A, et al. (1999). SIR97: a new tool for crystal structure determination and refinement. Journal of Applied Crystallography 32(1), pp.115-119.

Angoletta M. (1959). Derivaticarbonilici dell'iridio.-Nota III. Alogenuri di dicarbonilamminoiridio (I). Gazzette a Chimica Italiana 89, 2359-2370.

Bezman S.A, Bird PH, Fraser AR, Osborn JA. (1980). Metallacyclic complexes of iridium. Inorganic Chemistry 19(12), 3755-3763.

Blake AJ, Ebsworth EA, Murdoch HM, Yellowlees LJ. (1991). Vaska's compounddichloromethane solvate (1/2). Acta Crystallographica Section C: Crystal Structure Communications 47(3), 657-659, 47(3), 657-659.

Brandenburg K, Berndt M. (2001). DIAMOND. Visual Crystal Structure Information System, Crystal Impact, Version 2.1e.

Bruker SADABS Version 2004/1. (1998). Bruker AXS Inc. Area Detector Absorption Correction Software. Madison, WI, USA.

Bruker SAINT-Plus Version 6.02 (including XPREP) (1999). Bruker AXS Inc. AreaDetector Integration Software. Madison, WI, USA.

Burk MJ, Crabtree RH. (1986). A convenient general synthesis of trans-[IrCl(CO) (PR3)2]. Inorganic Chemistry 25(7), 931-932.

Ceriotti, A, Ciani GT, Sironi A. (1983). The crystal and molecular structure of transchlorocarbonylbis (triphenylphosphine) rhodium (I) in its monoclinic form. Journal of Organometallic Chemistry 247(3), 345-350.

Chaloner PA, Claver C, Hitchcock PB, Masdeu AM, Ruiz A. (1991). Orthorhombic crystal form of trans-carbonylchlorobis (triphenylphosphine) rhodium (I) dichloromethane solvate. Acta Crystallographica Section C: Crystal Structure Communications 47(6), 1307-1308. 
Chatt J, Duncanson LA. (1953). Olefin co-ordination compounds. Part III. Infrared spectra and structure: attempted preparation of acetylene complexes. Journal of the Chemical Society 2939-2947.

Chen YJ, Wang JC, Wang Y. (1991). Structure of trans-[Rh(CO)CI\{P(C6H5)3\}2]: a centrosymmetric triclinic phase. Acta Crystallographica Section C: Crystal Structure Communications 47(11), 2441-2442.

Churchill MR, Fettinger JC, Buttrey LA, Barkan MD, Thompson JS. (1988). An accurate X-ray diffraction study of Vaska's compound, trans-IrCl(CO)(PPh3)2, including resolution of the carbonyl/chloride disorder problem. Journal of Organometallic Chemistry, 340(2), 257-266., 340(2), 257-266.

Churchill MR, Lake CH, Miller CA, Atwood JD. (1994). Crystal structure of transcarbonylchlorobis-(tricyclohexylphosphine) iridium (I), trans-Ir(CO)Cl-[P(cycloC6H11)3]2, a disordered species. Journal of Chemical Crystallography 24(8), 557-560.

Clarke ML, Holliday GL, Slawin AM, Woollins JD. (2002). Highly electron rich alkyland dialkyl-N-pyrrolidinyl phosphines: an evaluation of their electronic and structural properties. Journal of the Chemical Society, Dalton Transactions, (6) 1093-1103.

Collman JP, Hegedus LS. (1980). Principles and Application of Organotransition Metal Chemistry. Mill Valley, California: University Science Books.

Davis WL, Muller A. (2012). [4-(Dimethylamino) phenyl] diphenylphosphine selenide. Acta Crystallographica Section E: Structure Reports Online 68(11), 03153-03154.

Del Pra A, Zanotti G, Segala P. (1979). Trans-Carbonylbis (Triphenylphosphine) Rhodium (I) Chloride, C37H30ClOP2Rh. Crystal Structure Communications 8(4), 959-964.

Dewar MJ. (1951). A review of the pi-complex theory. Bulletin de la Sociéte Chimique de France 18, C71-C79.

Dunbar KR, Haefner SC. (1992). Crystallographic disorder in the orthorhombic form of carbonyl(chlorobis(triphenylphosphine)rhodium: relevance to the reported structure of the paramagnetic impurity in Wilkinson's catalyst. Inorganic Chemistry 31 (17), 3676-3679.

Fernandez AL, Prock A, Giering WP. (2003). The QALE* Web Site. Retrieved from http://www.bu.edu/qale/

Frisch MJ, Trucks GW, Schlegel HB, Scuseria GE, Robb MA, Cheeseman JR, et al. (2004). Gaussian 03, Revision C.02.

Galding MR, Virovets AV, Kazakov IV, Scheer M, Smirnov SN, Timoshkin AY. (2016). Diminished electron density in the Vaska-type rhodium(I) complex trans[Rh(NCBH3)(CO)(PPh3)2]. Acta Crystallographica C Structural Chemistry 72(7), 514-517.

Grobbelaar E, Lötter S, Visser HG, Conradie J, Purcell W. (2009). Investigation of the electron density of iridium (I) Vaska-type complexes using DFT calculations and structural results: Structure of trans-carbonyl-chloro-bis (tricyclohexylphosphine)-iridium (I). Inorganica Chimica Acta 362(11), 39493954 .

Groom CR, Bruno IJ, Lightfoot MP, Ward SC. (2016). The Cambridge structural database. Acta Crystallographica Section B: Structural Science Crystal Engineering and Materials, 72(2), 171-179.

Kemp G, Roodt A, Purcell W. (1995). A new crystalline form of the rhodium (I) Analog of Vaska complex-crystal-structure of trans-chlorocarbonylbis (Triphenylphosphine) rhodium (I). Rhodium Express (12), 21-26.

Kirss R. (2013). Fifty years of Vaska's compound (1). Bulletin for the History of Chemistry 52-60.

Kuwabara E, Bau R. (1994). trans-Carbonylchlorobis (tricyclohexylphosphine) iridium (I). Acta Crystallographica Section C: Crystal Structure Communications 50(9), 1409-1411.

Limaye AC, Gadre SR. (2001). UNIVIS-2000: an indigenously developed comprehensive visualization package. Current Science (India) 80, 1296-1300.

Lorenzini F, Qian S, Blake AJ, Marchetti F, Saunders GC, Marr AC. (2016). Private communication.

McCleverty JA, Wilkinson G, Lipson LG, Maddox ML, Kaesz HD. (1990). Tetracarbonyldichlorodirhodium. Inorganic Syntheses: Reagents for Transition Metal Complex and Organometallic Syntheses 28, 84-86.

Mills AM, Van der Vlugt JI, Vogt D, Spek A. (2002). Private Communication.
Momma K, Izumi F. (2011). VESTA 3 for three-dimensional visualization of crystal, volumetric and morphology data. Journal of Applied Crystallography 44(6), 1272-1276.

Muller AJ, Otto S, Roodt A. (2008). Rapid phosphorus(III) ligand evaluation utilising potassium selenocyanate. Dalton Transactions 650-657.

Müller TE, Mingos DM. (1995). Determination of the Tolman cone angle from crystallographic parameters and a statistical analysis using the crystallographic data base. Transition Metal Chemistry 20(6), 533-539.

Ohgomori Y, Watanabe Y. (1990). The Vaska-type rhodium complexes, transRhX(CO)L2. Inorganic Syntheses Vol 27, 290-293.

Osborn JA, Jardine FH, Young JF, Wilkinson G. (1966). The preparation and properties of tris(triphenylphosphine)halogenorhodium(I) and some reactions thereof including catalytic homogeneous hydrogenation of olefins and acetylenes and their derivatives. Journal of the Chemical Society (A) 1711-1732.

Otto S, Roodt A, Smith J. (2000). Steric effects induced by ferrocenyl in tertiary organophosphines: crystal structure of trans-chloromethylbis (ferrocenyldiphenylphosphine) palladium (II) benzene disolvate. Inorganica Chimica Acta 303(2), 295-299.

Phasha ZH, Makhoba S, Muller A. (2012). Dicyclohexyl [4-(dimethylamino) phenyl] phosphine selenide. Acta Crystallographica Section E: Structure Reports Online 68(1), 0243-0243.

Pignolet LM. (1983). Homogeneous Catalysis with Metal Phosphine Complexes. New York: Plenum press.

Ren X, Zheng Z, Zhang L, Wang Z, Xia C, Ding K. (2017). Rhodium complex catalyzed hydroformylation of olefins with $\mathrm{CO} 2$ and hydrosilane. Angewandte Chemie International Edition 56(1), 310-313.

Rheingold AL, Geib SJ. (1987). trans-Carbonylchlorobis (triphenylphosphine) rhodium (I), a new polymorph. Acta Crystallographica Section C: Crysta Structure Communications 43(4), 784-786.

Roodt A, Otto S, Steyl G. (2003). Structure and solution behaviour of rhodium(I) Vaska-type complexes for correlation of steric and electronic properties of tertiary phosphine ligands. Coordination Chemistry Reviews 245, 121-137.

Sharma P, Cabrera A, Le Lagadec R, Manzo RL, Espinosa G, Sharma M, Arias JL (1988). Acta Ciencia Indica, Series Chemistry 24, 137

Smoleński P, Kirillov AM, Guedes da Silva MF, Pombeiro AJ. (2011). Transformations of the Vaska-type complex trans-[RhCl(CO)(PTA)2] (PTA $=1,3,5$-triaza7-phosphaadamantane) during stepwise addition of $\mathrm{HCl}$ : Synthesis, characterization and crystal structure of trans-[RhCl2(PTA)(PTAH)]. Inorganica Chimica Acta 378, 342-346.

Suresh CH, Koga N. (2002). Quantifying the electronic effect of substituted phosphine ligands via molecular electrostatic potential. Inorganic chemistry 41(6), 1573-1578.

Taverner BC. (1996). Improved algorithm for accurate computation of molecular solid angles. Journal of Computational Chemistry 17(14), 1612-1623.

Tolman CA. (1977). Steric effects of phosphorus ligands in organometallic chemistry and homogeneous catalysis. Chemical Reviews 77(3), 313-348.

Vallarino L. (1957). Carbonyl complexes of rhodium. Part I. Complexes with triarylphosphines, triarylarsines, and triarylstibines. Journal of the Chemical Society 2287-2292.

Van Leeuwen PW. (2004). Homogeneous Catalysis, Understanding the Art. The Netherlands: Kluwer Academic Publishers.

Vaska L, DiLuzio JW. (1961). Carbonyl and hydrido-carbonyl complexes of iridium by reaction with alcohols hydrido complexes by reaction with acid. Journal of the American Chemical Society 83, 2784-2785.

Warsink S, Koen R, Roodt A. (2011). trans-Carbonylchloridobis (tri-otolylphosphane$\kappa \mathrm{P})$ rhodium (I). Acta Crystallographica Section E: Structure Reports Online 67(12), m1666-m1666.

Wilson MR, Prock A, Giering WP, Fernandez AL, Haar CM, Nolan SP. (2002). P. effects involving Rh- PZ3 compounds. The quantitative analysis of ligand effects (QALE). Organometallics 21(13), 2758-2763.

Winterton N, Leigh, J (2002). Modern Coordination Chemistry: The Legacy of Joseph Chatt Springer Verlag. 